\title{
Effect of Iron Oxide Nanoparticles on Vascular Function and Nitric Oxide Production in Acute Stress-Exposed Rats
}

\author{
Silvia LÍŠKOVÁ ${ }^{\mathbf{1}, 2}$, Peter BALIŠ ${ }^{1}$, Andrea MIČUROVÁ ${ }^{1}$, Michal KLUKNAVSKÝ ${ }^{\mathbf{1}}$, Monika \\ OKULIAROVÁ ${ }^{3}$, Angelika PÚZSEROVÁ ${ }^{1}$, Martin ŠKRÁTEK ${ }^{4}$, Ivan SEKAJ ${ }^{5}$, \\ Jan MAŇKA ${ }^{4}$, Pavol VALOVIČČ ${ }^{1,6}$, Iveta BERNÁTOVÁ ${ }^{1}$ \\ ${ }^{1}$ Institute of Normal and Pathological Physiology, Centre of Experimental Medicine, Slovak \\ Academy of Sciences, Bratislava, Slovak Republic, ${ }^{2}$ Institute of Pharmacology and Clinical \\ Pharmacology, Faculty of Medicine, Comenius University, Bratislava, Slovak Republic, \\ ${ }^{3}$ Department of Animal Physiology and Ethology, Faculty of Natural Sciences, Comenius \\ University, Bratislava, Slovak Republic, ${ }^{4}$ Institute of Measurement Science, Slovak Academy of \\ Sciences, Bratislava, Slovak Republic, ${ }^{5}$ Institute of Robotics and Cybernetics, Faculty of Electrical \\ Engineering and Information Technology, Slovak University of Technology, Bratislava, Slovak \\ Republic, ${ }^{6}$ Institute of Physiology, Czech Academy of Sciences, Prague, Czech Republic
}

Received August 31, 2020

Accepted October 13, 2020

Epub Ahead of Print November 2, 2020

\section{Summary}

We investigated whether polyethylene glycol-coated $\mathrm{Fe}_{3} \mathrm{O}_{4}$ nanoparticles (IONs), acute stress and their combination modifies vascular functions, nitric oxide synthase (NOS) activity, mean arterial pressure (MAP) as well as hepcidin and ferritin $\mathrm{H}$ gene expressions in Wistar-Kyoto rats. Rats were divided into control, ION-treated rats (1 mg Fe/kg i.v.), repeated acute air jet stressexposed rats and IONs-and-stress co-exposed rats. Maximal acetylcholine (ACh)-induced and sodium nitroprusside (SNP)-induced relaxations in the femoral arteries did not differ among the groups. IONs alone significantly elevated the $\mathrm{N}^{\omega}$-nitroL-arginine methyl ester (L-NAME)-sensitive component of ACh-induced relaxation and reduced the sensitivity of vascular smooth muscle cells to SNP. IONs alone also elevated NOS activity in the brainstem and hypothalamus, reduced NOS activity in the kidneys and had no effect in the liver. Acute stress alone failed to affect vascular function and NOS activities in all the tissues investigated but it elevated ferritin $\mathrm{H}$ expression in the liver. In the ION-and-stress group, NOS activity was elevated in the kidneys and liver, but reduced in the brainstem and hypothalamus vs. IONs alone. IONs also accentuated air jet stress-induced MAP responses vs. stress alone. Interestingly, stress reduced ION-originated iron content in blood and liver while it was elevated in the kidneys. In conclusion, the results showed that 1) acute administration of IONs altered vascular function, increased L-NAME-sensitive component of ACh-induced relaxation and had tissue-dependent effects on NOS activity, 2) ION effects were considerably reduced by co-exposure to repeated acute stress, likely related to decrease of ION-originated iron in blood due to elevated decomposition and/or excretion.

\section{Key words}

Vascular function - Acute stress - Iron oxide nanoparticles • Blood pressure $\bullet$ Nitric oxide $\bullet$ Polyethylene glycol

\section{Corresponding authors}

Silvia Lišková, Institute of Pharmacology and Clinical Pharmacology, Faculty of Medicine, Comenius University, Sasinkova 4, 81108 Bratislava, Slovak Republic, E-mail: silvia.liskova@gmail.com, and Iveta Bernátová, Institute of Normal and Pathological Physiology, Centre of Experimental Medicine, Slovak Academy of Sciences Sienkiewiczova 1, 81109 Bratislava, Slovak Republic. E-mail: iveta.bernatova@savba.sk

\section{Introduction}

The last decade of investigations of metal 
nanoparticles (NPs), including superparamagnetic iron oxide nanoparticles (IONs), have revealed their potential for various biomedical applications, from magnetic resonance imaging contrast agents including detection of bacteria or viruses to drug delivery systems and the usage of magnetic hyperthermia in cancer treatment (Andrade et al. 2020, Poller et al. 2018). However, the properties and biological effects of IONs vary depending on their shape, size, surface modification, etc. In general, smaller nanoparticles $(1-20 \mathrm{~nm})$ seem to enter and exit the cell more efficiently and infiltrate organs better than larger ones, spherical NPs are less toxic than rod-shaped ones and positively charged NPs exhibit much higher rates of endocytosis and remain in the cell longer than negative or neutrally charged ones (Oh and Park 2014).

Bare IONs are toxic mainly due to the induction of haemolysis, oxidative stress and DNA breakdown (Andrade et al. 2020, Dalzon et al. 2020). Thus, various coatings have been developed to reduce ION cytotoxicity. Hydrophilic polymer polyethylene glycol (PEG) is a neutral biocompatible polymer, which improves the dispersion of IONs in water, improves the biodistribution of NPs in an organism and increases blood circulation time (Yoffe et al. 2013). The PEGylation of nanoparticles has also been shown to reduce hemotoxic effects, haemolysis, liver uptake and immunogenicity (Lee et al. 2005, Suk et al. 2016). Intravenous application is the common route for IONs in therapeutic applications, such as drug delivery, nanocarriers and diagnostic tools (Dukhinova et al. 2019). The main ways to eliminate IONs are through renal and hepatic excretions (Almeida et al. 2011, Longmire et al. 2008). However, the iron released from decomposed IONs can also enter cellular iron metabolism (Poller et al. 2018) and thus can affect iron homeostasis. Elevated iron levels results in the elevation of hepatic hepcidin release, which is the main regulator of iron homeostasis as well as in the elevation of ferritin synthesis, which is a main iron-storage protein, in order to recover optimal iron concentrations in the tissues (De Domenico et al. 2010). In addition, ferritin levels can be altered in oxidative stress conditions (Torti and Torti 2002) which is often induced by NPs.

Endothelium, the inner monolayer of blood vessels, produces various substances collectively termed endothelium-derived factors, which modulate vascular functions and thus blood pressure (Bernatova 2014). Endothelial cells are directly exposed to IONs when administered intravenously. Su et al. observed ION uptake to endothelial cells in vitro, in which IONs were located in the cytoplasm (Su et al. 2012). ION uptake was also detected in the endothelial cells of cerebral arteries in vitro in which IONs induced the release of reactive oxygen species, DNA damage and autophagy (Kenzaoui et al. 2012). ION accumulation in endothelial cells can modify the function of the endothelium and/or vascular wall by activating inflammation, disrupting cellular respiration and inducing oxidative stress and apoptosis (Yarjanli et al. 2017) and altering nitric oxide (NO) production. Astanina et al. observed reduced NO production in cultured endothelial cells after their incubation with recommended doses of IONs approved for medical purposes (Astanina et al. 2014). Zhu et al., in contrast, observed that IONs generated oxidative stress, increased NO production and induced the loss of mitochondria membrane potential and apoptosis in endothelial cell cultures (Zhu et al. 2010). As IONs in concentrations relevant for in vivo applications can affect endothelial cells, their influence on the endothelium and vascular wall functions must be investigated to understand their possible cardiovascular side effects in humans (Astanina et al. 2014).

Stress is considered a risk factor associated with the development of various chronic diseases, including cardiovascular diseases. Despite the variability of stressors and their effects on organisms, sudden stressors can activate the autonomic nervous system, which is associated with increased blood pressure (BP) and heart rate (HR). On the other hand, NO is a major depressor factor that attenuates BP increases via attenuation of sympathetic nervous system (SNS) activation along with the renin-angiotensin-aldosterone system (Kumagai et al. 2012). Vascular and/or endothelial function can also be altered by stress (Puzserova and Bernatova 2016). Despite considerable differences between in vitro and in vivo studies that have investigated the influence of stressors on the production of endothelium-derived factors (Bernatova 2014), endothelium-derived NO has been suggested as a stress-relieving molecule (Stefano et al. 2006). Thus, stress may be a factor that considerably modifies the effect of treatment via modulation of vascular functions and feedback effect on the autonomic nervous system, as demonstrated by acute pharmacological adrenalectomy (Bencze et al. 2020). In addition, excessive NO production due to the activation of inducible NO synthase (NOS) contributes to vascular hypo-reactivity, reduces systemic resistance and decreases blood pressure (El Hadi et al. 2020).

In this study, we used acute air jets to induce 
stress reactions associated with prominent BP increase during air jet to investigate the modulatory effect of repeated acute stress on ION administration. Air jet stress results in psycho-emotional stress, which causes a characteristic defence reaction with increases in BP, HR and renal sympathetic nerve activity (Bernatova et al. 2016, Kanbar et al. 2007, Yamazato et al. 2006). It is well known that acute stress alters neurohumoral mechanisms, which leads to changes in vascular function and thus stress alters blood flow and distribution (Wang et al. 2005). All these factors should be taken into account during IONs application in humans.

The femoral artery is an important branch of the iliac artery that irrigates lower-limb skeletal muscles and peripheral tissues. It is a unique blood vessel with long conduction, high-flow resistance and a striking relevance for medical interventions (Mewissen 2005). Femoral artery tone regulation depends on endothelium-derived relaxing and contracting factors (Bencze et al. 2015, Dobias et al. 2016, Líšková et al. 2007), thus representing an ideal artery for studying vascular responses in various experimental approaches. One such approach involve the inhibition of NOS leading to the impairment of NO release, which in turn may unmask the effect of endothelium-derived contracting factors (EDCFs) (Liskova et al. 2011). This is of particular importance because the application of $\mathrm{N}^{\omega}$-nitro-Larginine methyl ester (L-NAME) allows the assessment of the L-NAME-sensitive component of concentrationresponse curves induced by acetylcholine ( $\mathrm{ACh}$ ). The L-NAME-sensitive component has NO-dependent and EDCFs-dependent part and thus after L-NAME application the isolated femoral arteries react with enhanced concentration-dependent contractions (Liskova et al. 2011) or impaired concentration-response curves of endothelium-dependent ACh-induced relaxations (Puzserova et al. 2013). Due to intravenous administration of IONs in clinical applications, it is of great importance to study the effect of IONs on endothelial cells as nanoparticles per se or iron released from them may penetrate the vascular wall and thus change vascular functions. Furthermore, it is reasonable to investigate the joint influence of acute stress on vascular function and NOS activity as diseases, hospital environments and/or intravenous applications of IONs are always associated with certain levels of stress in patients.

Thus, in this study we investigated the effect of i.v. administration of IONs on vascular functions of the femoral arteries of normotensive rats, NOS activity in the tissues (kidneys, liver, brainstem and hypothalamus) and on BP at rest ( 100 min-post infusion, at the end of the experiment). We also investigated acute stress-induced $\mathrm{BP}$ and HR responses in ION-treated rats because of the possibility of stress conditions during the use of IONs in medical practice. In addition, we determined the effect of IONs on gene expression of hepcidin (HAMP) and ferritin (FTH1) in the liver and kidneys (involved in excretion of IONs) as well as the effect of repeated acute stress on ION-originated iron content in these organs and blood.

\section{Materials and Methods}

Animals and treatment

All the procedures used in this study were approved by the State Veterinary and Food Administration of the Slovak Republic in accordance with the European Union Directive 2010/63/EU.

Wistar-Kyoto (WKY) male rats 12-16 weeks old, $n=6-7$ per group, were used in this study. Rats were housed under standard conditions at $22-24{ }^{\circ} \mathrm{C}$ in a $12-\mathrm{h}$ light/dark cycle and fed with pelleted diet Altromin formula 1324, variant P (Altromin Spezialfutter, Lage, Germany) and tap water ad libitum.

A day before the experiment, all rats had two catheters implanted under 2.5-3.5\% isoflurane anaesthesia, as described previously (Behuliak et al. 2013). All rats were also pre-treated with meloxicam (Meloxidolor, Le Vet Beheer B.V., Oudewated, Nederland) at $2 \mathrm{mg} / \mathrm{kg} \mathrm{s.c.} \mathrm{before} \mathrm{surgery} \mathrm{to} \mathrm{prevent} \mathrm{post-}$ surgical pain. Fine-bore polyethylene catheters (Smiths Medical International Ltd, Kent, UK) were inserted into the left carotid artery (internal diameter $0.58 \mathrm{~mm}$ ) to determine BP and HR and the jugular vein (internal diameter $0.28 \mathrm{~mm}$ ) for i.v. administration of IONs (dispersed in saline) or saline (in control and stressed rats), respectively. Catheters were exteriorised in the interscapular region, and rats were allowed to recover from anaesthesia for approximately 20-24 h.

Rats were divided into four groups: control (Cont), ultra-small superparamagnetic iron oxide $\left(\mathrm{Fe}_{3} \mathrm{O}_{4}\right)$ nanoparticle (ION)-treated rats (IONs), repeated acute air jet stress-exposed rats (Str) and rats co-exposed to IONs and repeated air jet stress (IONs + Str). Control and stressed rats were given 10-min infusions of saline starting approximately $30 \mathrm{~min}$ from the beginning of BP recording (Fig. 1). IONs and IONs + Str rats were given 10-min infusions of PEG-coated IONs. Commercially 
available PEG-coated IONs were purchased from SigmaAldrich (Bratislava, Slovakia, cat. No. 747408). IONs concentration was $1 \mathrm{mg} \mathrm{Fe} / \mathrm{ml}$ and they were dispersed in water. The size of IONs confirmed by the transmission electron microscope was $28-32 \mathrm{~nm}$, the zeta potential was $-12 \mathrm{mV}$, polydispersity index was 0.1 and the hydrodynamic size was about $45 \mathrm{~nm}$ (declared by the manufacturer). IONs were autoclaved at $121^{\circ} \mathrm{C}$ for $30 \mathrm{~min}$ and before i.v. application they mixed with sterile saline to reach a final dose of $1 \mathrm{mg}$ of $\mathrm{Fe} / \mathrm{kg}$ of body weight. Properties of IONs before their administration to rats and their presence in the tissues (proven by biomagnetometric method) are shown in other study (Skratek et al. 2020).

The experiments were performed in a quiet room to avoid any non-specific stimuli affecting BP and HR, which were recorded with the sampling rate of $1 \mathrm{kHz}$. During the experiments, the conscious rats were placed in a plastic box with dark walls and a transparent lid $27 \times 14$ $\times 9 \mathrm{~cm}$ in size, which allowed the rats free movement. An arterial catheter was attached to the BP-recording device PowerLab system (ADInstruments, Bella Vista, Australia), and BP was allowed to stabilise for at least
15 min. BP and HR were recorded during the entire experiment, basal mean arterial pressure (MAP) and HR were calculated as the average values of a 200-sec segment between 16-20 min of the recording and end MAP and HR were calculated as the average values of a 200-sec segment between 138-142 $\min$ of the experiment. The peak values of MAP and HR were also calculated during each air jet (AJ) session as the maximal values of the given variable during air jet compared with the average pre-AJ value determined during 200-sec segments preceding the corresponding AJ session (Fig. 1). Repeated acute AJ stress was produced by a 5-sec pulse of air at the forehead of the rat in the Str and IONs + Str groups as described previously (Bernatova et al. 2016, Nakamoto et al. 2007). Each rat in these two groups was exposed to three sessions of 5-sec AJ: 1) $10 \mathrm{~min}$ before the infusion, 2) $10 \mathrm{~min}$ after the infusion and 3) $90 \mathrm{~min}$ after the infusion. Variable time points were chosen to maintain the unpredictability of the stressor (Bernatova et al. 2016). BP recordings were transformed into a MATLAB $\AA$ environment for further analysis. MAP was calculated as $\mathrm{MAP}=$ diastolic $\mathrm{BP}+$ 1/3 (systolic BP - diastolic BP) (Bernatova et al. 2016).

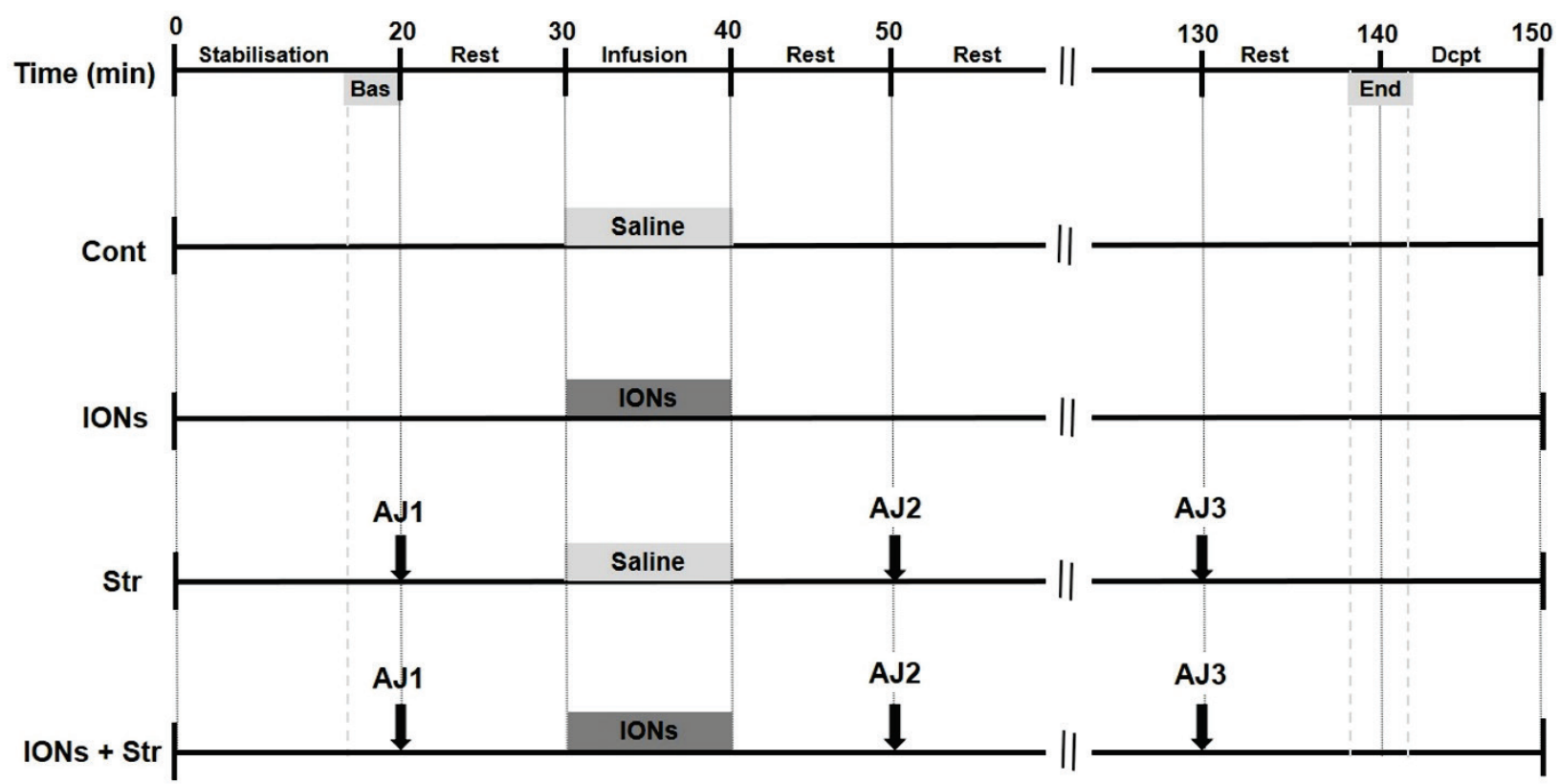

Fig. 1. Time course of the experimental protocol. Stress was induced by 5 -sec air jets (AJ) as described previously (Bernátová et al. 2016). Basal recordings of blood pressure and heart rate were determined at the beginning (Bas) and at the end (End) of the experiment as the average values of approximately $200-\mathrm{sec}$ segments between 16-20 min and 138-142 min of the experiment. Then the animals were decapitated (Dcpt).

At the end of the protocol, rats were exposed to brief $\mathrm{CO}_{2}$ anesthesia and decapitated within $5 \mathrm{~min}$ of the final MAP recording. Trunk blood for determination of
IONs was collected into Eppendorf test tubes and kept at $-80{ }^{\circ} \mathrm{C}$. The NOS activity was determined in fresh tissue homogenates of the brainstem, hypothalamus, kidney and 
liver. The remaining parts of dissected kidneys and liver were frozen in liquid nitrogen and kept at $-80{ }^{\circ} \mathrm{C}$ for further analyses. Femoral arteries were stored in fridge at $4{ }^{\circ} \mathrm{C}$ and used the same day for vessel myography.

\section{Plasma corticosterone}

Plasma corticosterone was determined in $50 \mu \mathrm{l}$ blood samples collected from the carotid artery (at the end of experiment) into ethylenediaminetetraacetic acidcoated test tubes and centrifuged for $10 \mathrm{~min}(850 \mathrm{~g}$, $4{ }^{\circ} \mathrm{C}$ ). Plasma samples were stored at $-80^{\circ} \mathrm{C}$ until further analysis. Plasma corticosterone levels were determined using the Corticosterone Rat/Mouse ${ }^{125} \mathrm{I}$ radioimmunoassay kit (DRG Instruments $\mathrm{GmBH}$, Germany), according to the manufacturer's instructions. All samples were measured in a single assay with the intra-assay variation coefficient of $4 \%$. The assay sensitivity was $6.3 \mathrm{ng} / \mathrm{ml}$.

\section{Nitric oxide synthase activity}

NOS activity was determined in $20 \%$ of fresh tissue homogenates (w:v) of the brainstem, hypothalamus, kidneys and liver as described previously with minor modifications (Puzserova et al. 2013). Briefly, tissues were collected into ice-cold buffer $(0.05$ mol/1 Tris- $\mathrm{HCl}, \mathrm{pH} 7.4$, containing $1 \%$ protease inhibitor cocktail [104 mmol/1 of 4-(2-aminoethyl)benzenesulfonyl fluoride, $80 \mathrm{mmol} / \mathrm{l}$ aprotinin, $4 \mathrm{mmol} / \mathrm{l}$ bestatin, $1.4 \mathrm{mmol} / \mathrm{l}$ of E-64, $2 \mathrm{mmol} / \mathrm{l}$ leupeptin and $1.5 \mathrm{mmol} / \mathrm{l}$ of pepstatin A]). The tissues were then immediately homogenised using an Ultra-Turrax homogeniser at $4{ }^{\circ} \mathrm{C}$ and centrifuged $\left(4^{\circ} \mathrm{C}, 10 \mathrm{~min}, 3000 \mathrm{~g}\right)$. After centrifugation, NO synthase activity was determined in the supernatants by the conversion of [3H]-L-arginine (specific activity $5 \mathrm{GBq} / \mathrm{mmol}, \sim 100,000 \mathrm{dpm}$, ARC, St. Louis, MO, USA) to [3H]-L-citrulline in the presence of $50 \mathrm{mmol} / \mathrm{l}$ Tris $/ \mathrm{HCl}, \mathrm{pH} 7.4$ (containing $10 \mu \mathrm{mol} / 1$ L-arginine, $5 \mu \mathrm{g} / \mathrm{ml}$ calmodulin, $0.5 \mathrm{mmol} / \mathrm{l} \beta$-NADPH, $0.6 \mathrm{mmol} / 1$ tetrahydrobiopterin, $4 \mu \mathrm{mol} / 1$ flavin adenine dinucleotide, $4 \mu \mathrm{mol} / \mathrm{l}$ flavin mononucleotide, $1 \mathrm{mmol} / \mathrm{l}$ $\mathrm{Ca}^{2+}$ and $1 \mathrm{mmol} / \mathrm{M} \mathrm{Mg}^{2+}$ ) in a total volume of $100 \mu \mathrm{l}$. After $20 \mathrm{~min}$ of incubation at $37^{\circ} \mathrm{C}$, the reaction was stopped by adding $1 \mathrm{ml}$ of ice-cold stop solution (containing $20 \quad \mathrm{mmol}$ 4-(2-hydroxyethyl)-1piperazineethanesulfonic acid, $\mathrm{pH}$ 5.5, 1 mmol/1 L-citrulline, $2 \mathrm{mmol} / \mathrm{l}$ EDTA and $2 \mathrm{mmol} / \mathrm{l}$ EGTA). Then $1 \mathrm{ml}$ of the mixture was applied to $1.5 \mathrm{ml}$ Dowex 50WX-8 columns ( $\mathrm{Na}^{+}$-form). [3H]-L-citrulline was eluted by $1.5 \mathrm{ml}$ of deionised water and determined by liquid scintillation counting (TriCarb, PerkinElmer). NO synthase activity was expressed as pkat per gram of protein. The protein concentration was determined using the Lowry method.

\section{Determination of vascular functions}

Isolated and cleaned fresh femoral arteries with intact endothelium were cut into segments and placed in a Mulvany-Halpern isometric myograph (Dual Wire Myograph system 410A, Danish Myo Technology A/S, Aarhus, Denmark). The myograph chambers were filled with modified Krebs-Henseleit solution (in $\mathrm{mmol} / \mathrm{l}$ : $119 \mathrm{NaCl}, 4.7 \mathrm{KCl}, 1.17 \mathrm{MgSO}_{4} .7 \mathrm{H}_{2} \mathrm{O}, 25 \mathrm{NaHCO}_{3}$, $1.18 \mathrm{KH}_{2} \mathrm{PO}_{4}, \quad 0.03 \quad \mathrm{Na}_{2}$ EDTA, $2.5 \mathrm{CaCl}_{2} .2 \mathrm{H}_{2} \mathrm{O}$, 5.5 glucose, $37{ }^{\circ} \mathrm{C}$, pH 7.4) and bubbled with $95 \% \mathrm{O}_{2}$ and $5 \% \mathrm{CO}_{2}$. The inner arterial diameter of femoral arteries was set to $90 \%$ of the diameter predicted for the pressure of $100 \mathrm{mmHg}$ in the wire myograph. After $30 \mathrm{~min}$ of stabilization, the arteries achieved their basal tones. To test the viability of isolated arteries, the arteries were incubated in a depolarizing solution (125 mmol/1 $\mathrm{K}^{+}, \mathrm{NaCl}$ was exchanged for an equimolar concentration of $\mathrm{KCl}$ ) for $2 \mathrm{~min}$. After being washed out, the experimental protocol was carried out as described in another study (Puzserova et al. 2013). Briefly, after the washing and stabilization of the basal tone, serotonin (5-hydroxytryptamine, 5-HT)-induced contraction $\left(10^{-6} \mathrm{~mol} / \mathrm{l}\right)$ was determined. It was followed by determination of the total endothelium-dependent ACh-induced relaxations by cumulatively adding ACh concentrations from $10^{-9}$ to $10^{-5} \mathrm{~mol} / 1$. After $20 \mathrm{~min}$ of washing out, the same approach was applied again in the presence of the non-specific NO synthase inhibitor L-NAME $\left(3.10^{-4} \mathrm{~mol} / \mathrm{l}, 30 \mathrm{~min}\right.$ pre-incubation) to determine 5-HT-induced contractions in the presence of NO synthase inhibitor as well as the NO-independent component of endothelium-dependent relaxation. After repeating washing, the third concentration-response curve was performed by cumulatively adding exogenous NO donor (sodium nitroprusside, SNP) in concentrations of $10^{-9}$ to $10^{-5} \mathrm{~mol} / 1$ to determine the endotheliumindependent relaxations produced by exogenous $\mathrm{NO}$ on vascular smooth muscle cells (VSMCs).

Pharmacodynamic characteristics - i.e. halfmaximal effective concentration $\left(\mathrm{EC}_{50}\right.$, expressed as $-\log \mathrm{mol} / \mathrm{l})$ and maximal relaxation $\left(\mathrm{E}_{\max }\right.$, expressed as a percentage of pre-contraction) - were calculated for each ACh- and SNP-induced concentration-response curve according to the Hill equation using the fitting 
model described in another studies (Liskova et al. 2014, Liskova et al. 2010). The L-NAME-sensitive component of ACh-induced relaxation was calculated as the difference between the area under the curve (AUC) of total ACh-induced relaxation and AUC of the L-NAMEresistant $\mathrm{ACh}$-induced relaxation, i.e.

$$
\mathrm{AUC}_{\mathrm{L}-\mathrm{NAME} \text {-sensitive }}=\mathrm{AUC}_{\text {TotalACh }}-\mathrm{AUC}_{\mathrm{L}-\mathrm{NAME}-\text {-resistant }} .
$$

All chemicals used in the study were obtained from Sigma-Aldrich (Bratislava, Slovakia) unless stated otherwise.

\section{Determination of the ION-originated iron content}

After dissection, the tissues were cleaned out of the connecting tissue, washed out of blood in the saline solution and dried of saline solution using filtration paper. Trunk blood was collected into Eppendorf test tubes. Tissues as well as blood were frozen in the liquid nitrogen and kept at $-80{ }^{\circ} \mathrm{C}$ until further analyses. Before determination of relative iron content, tissue samples were mounted on $18 \mathrm{~cm}$ long and $0.2 \mathrm{~mm}$ in diameter copper wire. Blood samples were prepared as described previously and $10 \mu \mathrm{l}$ was dropped on paper (Kluknavsky et al. 2020). Then samples were vacuum dried for 1 hour, placed in plastic straw and the magnetic characteristics of the samples were measured by a Quantum Design SQUID magnetometer MPMS-XL 7AC. Determination of ION-originated $\mathrm{Fe}$ content in tissue and blood samples was done by measuring their hysteresis curves $(\mathrm{M}$ vs $\mathrm{H}$ dependence) measured at the temperature of $300 \mathrm{~K}$ and up to $1 \mathrm{~T}$ applied field. The iron content in the blood, liver and kidneys of IONs and IONs + Str groups was determined using the following relation:

$$
c\left[\frac{\mu g_{F e}}{g}\right]=\frac{M_{s}^{\prime} * m_{F e}}{M_{I O N S} * m_{s}} * 10^{6}
$$

where $c$ is the IONs-originated Fe content in the sample, $M_{S}{ }_{S}$ is sample magnetization (at $1 \mathrm{~T}$ ) after subtraction of magnetization of the control tissue, $m_{s}$ is the mass of the sample, $m_{\mathrm{Fe}}$ is the mass of iron in $10 \mu \mathrm{l}$ of IONs, $M_{I O N S}$ is magnetization of ION dispersion measured at temperature $300 \mathrm{~K}$ and magnetic field $1 \mathrm{~T}$. At this conditions, the method determines only IONs-originated $\mathrm{Fe}$ because magnetic characteristics of biogenic iron present in the tissue differs from those of nanoparticle dispersion of PEGylated IONs and magnetisation of biogenic iron was subtracted.

\section{Determination of the gene expression}

The gene expression levels of hepcidin (HAMP,
NM_053469.1) in the liver and ferritin heavy chain 1 (FTH1, NM_012848.2) in the liver and kidneys as well as expression of $B$-actin (housekeeping gene, NM_031144.3) were determined after mRNA isolation using a real-time quantitative polymerase chain reaction (RT-qPCR) as described previously (Kluknavsky et al. 2020). Gene-specific primers were designed using the PubMed program (Primer-BLAST) and database (Gene). The gene expressions were considered as the ratio of the given gene's expression to $\beta$-actin expression. The following primer pairs and melting temperatures were used to determine selected genes: HAMP (forward - CTA TCT CCG GCA ACA GAC GAG, reverse - TGT CTC GCT TCC TTC GCT TC, $60{ }^{\circ} \mathrm{C}$ ), FTH1 (forward - ACG TCT ATC TGT CCA TGT CTT GTT, reverse - GAA GAT TCG TCC ACC TCG CT, $60{ }^{\circ} \mathrm{C}$ ), $\beta$-actin (forward - CTC TGT GTG GAT TGG TGG CT, reverse - CGC AGC TCA GTA ACA GTC CG, $59^{\circ} \mathrm{C}$ ).

\section{Statistical analysis}

Statistical analysis was performed by two-way ANOVA (with IONs and stress as the independent factors) or two-way ANOVA for repeated measures ANOVA and Student's t-test, where appropriate. ANOVA analyses were followed by the Bonferroni post-hoc test, except the analysis of the release of EDCFs in the IONs group after ACh-administration, which was analysed by one-way ANOVA and Dunnett's test. The values were found to significantly differ when $\mathrm{p}<0.05$. The data were presented as mean \pm standard error of the mean (SEM). GraphPad Prism 5.0 (GraphPad Software, Inc., San Diego, CA, USA) was used for the statistical analyses.

\section{Results}

Mean arterial pressure, heart rate and plasma corticosterone

MAP and HR of all rats at the beginning of the experiment were $132 \pm 2 \mathrm{mmHg}$ and $330 \pm 6 \mathrm{bpm}$ $(n=27)$, and no significant differences among the groups in these parameters were observed. MAP was reduced significantly at the end of the experiment vs. basal values in rats co-exposed to IONs and air jet stress (IONs + Str) (Fig. 2A). HR was reduced significantly in control (Cont), ION-treated rats (IONs) and acute air jet stressexposed rats (Str) groups vs. the respective basal values (Fig. 2B).

MAP in the Cont, Str and IONs groups at the end of the experiment was $102 \pm 4 \%, 99 \pm 1 \%$ and $99 \pm$ $2 \%$ of basal MAP, respectively, which were not 
A
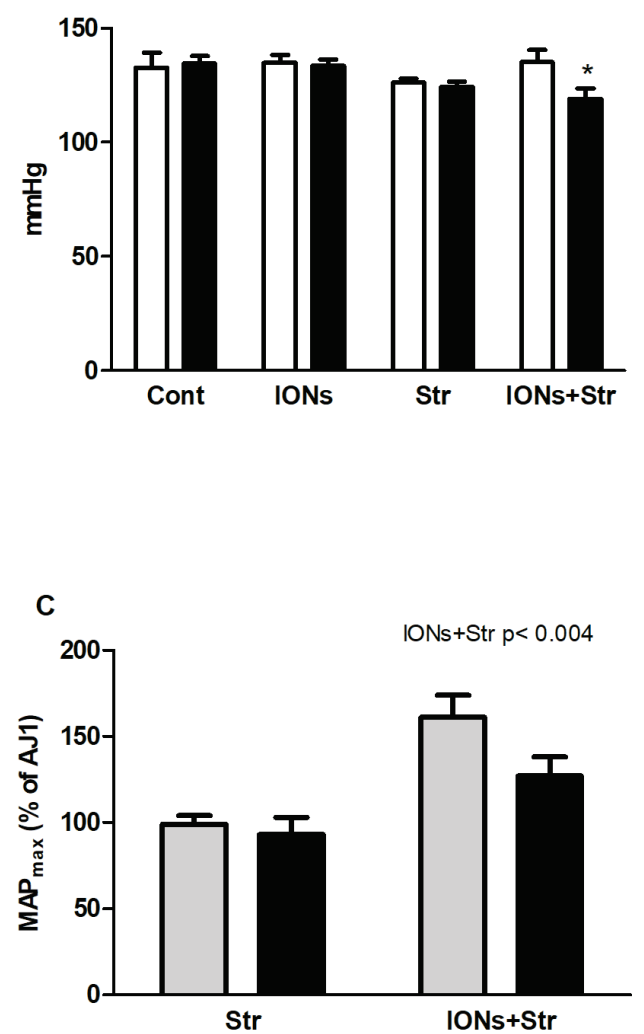

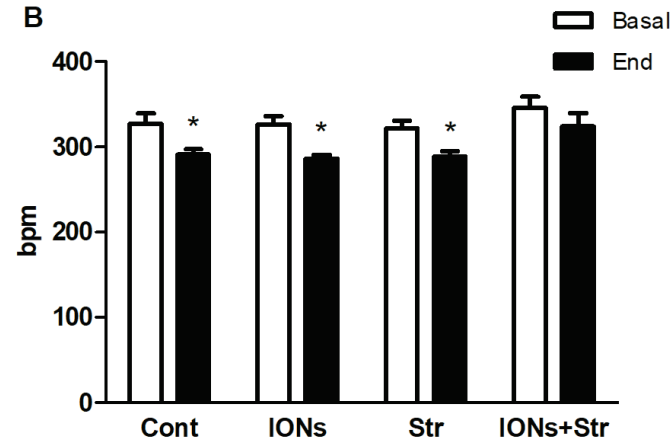

D

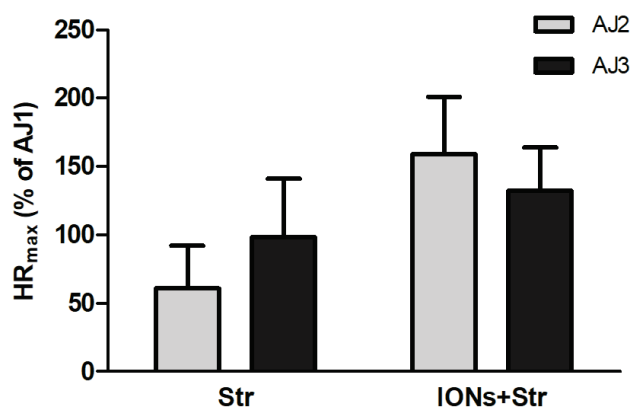

Fig. 2. Mean arterial pressure (A) and heart rate (B) at the beginning (basal) and the end of the experiment as well as peak values of mean arterial pressure $(\mathbf{C})$ and heart rate (D) during the second and third air jet session as a relative value of the first air jet session. The values represent the mean \pm SEM. ${ }^{*} p<0.05$ vs. basal in the respective group $(A, B)$. $p<0.004$ main effect of IONs + Str vs. Str group (C), $\mathrm{n}=6$ per group. Abbreviations. AJ: air jet, Cont: control group, IONs: rats treated with ultra-small superparamagnetic iron oxide nanoparticles, Str: rats exposed to repeated air jet stress, IONs + Str: rats treated with nanoparticles and co-exposed to repeated air jet stress.

significantly altered compared to basal MAP within each group. The MAP of rats in the IONs + Str group decreased significantly at the end of the experiment to $88 \pm 4 \%$ of basal MAP $(\mathrm{p}<0.02)$. HR in the Cont, Str and IONs groups at the end of the experiment was $89 \pm 3 \%$, $90 \pm 2 \%$ and $88 \pm 2 \%(\mathrm{p}<0.05$ vs. basal for all $)$, respectively. HR in the IONs + Str was $94 \pm 2 \%$ of basal HR (n.s.). The peak values of MAP and HR during the second and the third air jet (AJ) sessions were calculated as a percentage change of the response found during the first AJ (Fig. 2C, D). ANOVA analysis showed that IONs significantly increased the pressor responses to the stress produced by air jet (AJ2 and $\mathrm{AJ} 3$ ) when evaluated as the main effect of the IONs + Str co-application $\left(F_{(1,10)}=14.07, p<0.004\right)$, without the significant changes in peak HR responses.

Plasma corticosterone was significantly elevated in rats exposed to stress when determined as the main effect of stress in both stress-exposed groups $\left(\mathrm{F}_{(1,20)}=9.6\right.$, $\mathrm{p}<0.006$ vs. unstressed rats), while IONs did not affect this parameter (Fig. 3).

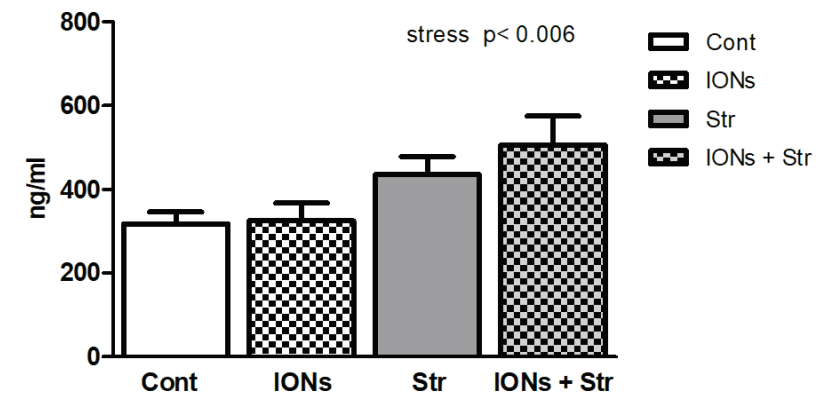

Fig. 3. Plasma corticosterone. Stress elevated plasma corticosterone when determined as the main effect of stress. The values represent the mean \pm SEM. ${ }^{*} p<0.006$ main effect of stress vs. unstressed rats. $\mathrm{n}=6$ per group. Abbreviations. Cont: control group, IONs: rats treated with ultra-small superparamagnetic iron oxide nanoparticles, Str: rats exposed to repeated air jet stress, IONs + Str: rats treated with nanoparticles and co-exposed to repeated air jet stress.

\section{NO synthase activity}

In the kidneys, NOS activity decreased in the IONs group by about $22 \% \quad(\mathrm{p}<0.03)$ vs. controls (Fig. 4A), while no changes were found in the liver (Fig. 4B). ION administration elevated NOS activity in the 
hypothalamus and brainstem by $34 \%(\mathrm{p}<0.03)$ and about $62 \%(\mathrm{p}<0.01)$, respectively, compared to the controls (Fig. 4C, D). In the IONs + Str group, NOS activity was significantly elevated in the kidneys $40 \%(\mathrm{p}<0.01)$ and liver $20 \%(\mathrm{p}<0.05)$ and reduced in the brainstem $55 \%$ $(\mathrm{p}<0.001)$ and hypothalamus $38 \%(\mathrm{p}<0.001)$ vs. the IONs group.

Stress alone had no effect on NOS activity in any tissue investigated vs. control. Similarly, no differences in NOS activity were found between Str and IONs + Str groups (Fig. 4).

\section{Contraction responses of the femoral arteries}

The mean internal diameter of all arterial segments used in this study was $717 \pm 7 \mu \mathrm{m}$ and did not differ significantly among the groups. The maximal depolarisation-induced contractions produced by the high concentration of potassium $\left(125 \mathrm{mmol} / 1 \mathrm{~K}^{+}\right)$in Cont, IONs, Str and IONs + Str were 8.24 $\pm 1.27,7.09 \pm 1.25$, $9.58 \pm 0.57$ and $9.31 \pm 1.14 \mathrm{mN} / \mathrm{mm}$, respectively, and no significant differences were observed among the groups. Maximal 5-HT-induced contractions in the absence of $\mathrm{N}^{\omega}$-nitro-L-arginine methyl ester (L-NAME) were similar among the groups (Fig. 5). Pre-incubation of the arteries with L-NAME significantly enhanced the 5-HT-induced contraction of femoral arteries in the Cont, Str and IONs + Str groups compared to the 5-HT-induced contraction in absence of L-NAME by approximately $36 \%, 38 \%$ and $18 \% \quad(p<0.05$ for all groups $)$, respectively. A correspondingly significant increase was not found in the IONs group.

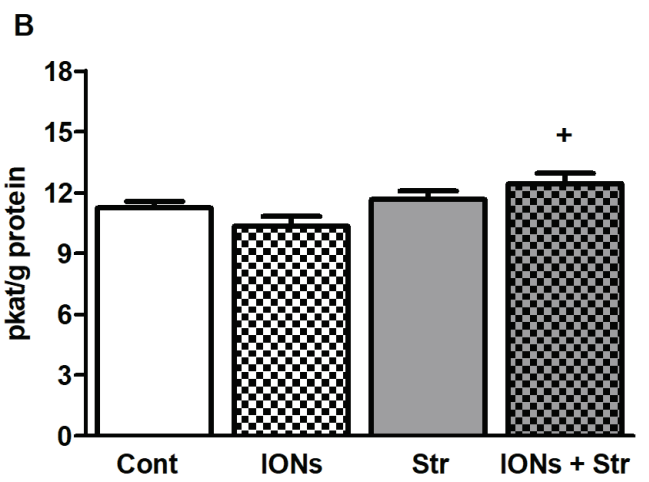

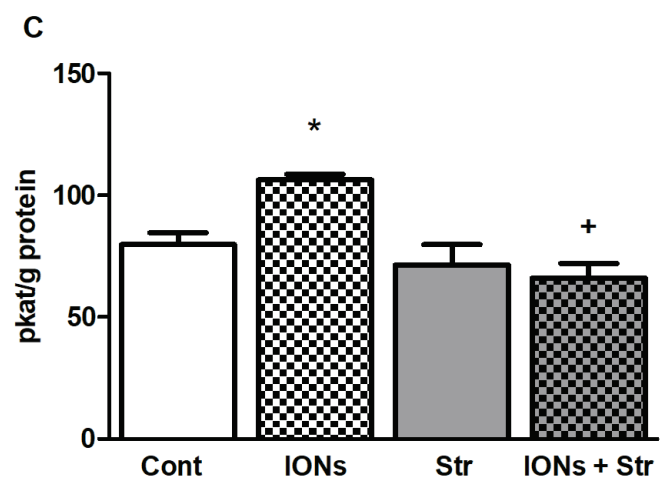

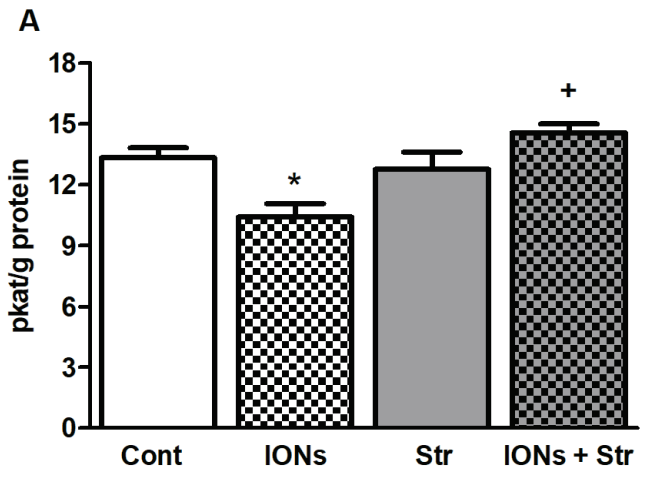

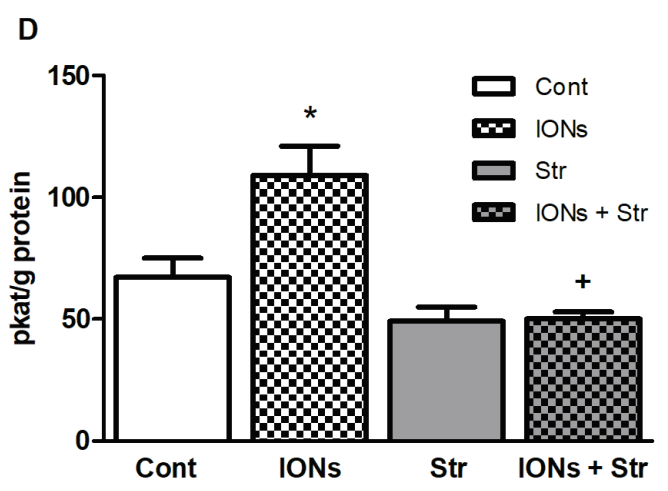

Fig. 4. Nitric oxide synthase activity in the kidneys (A), liver (B), hypothalamus (C) and brainstem (D). The values represent the mean \pm SEM. ${ }^{*} p<0.05$ vs. Cont group, ${ }^{+} p<0.05$ vs. IONs group, $n=6$ per group. Abbreviations. Cont: control group, IONs: rats treated with ultra-small superparamagnetic iron oxide nanoparticles, Str: rats exposed to repeated air jet stress, IONs + Str: rats treated with nanoparticles and co-exposed to repeated air jet stress.

\section{Relaxation responses of the femoral arteries}

The ACh-induced and SNP-induced concentration-response curves of 5-HT-precontracted femoral arteries are shown in Table 1 and Fig. 6.

Maximal ACh-induced relaxations $\left(\mathrm{E}_{\max }\right)$ were not altered by stress, IONs or their joint application vs. control (Table 1, Fig. 6A).

L-NAME significantly reduced ACh-induced relaxation $\left(\mathrm{F}_{(1,21)}=29.3, \mathrm{p}<0.0001\right)$ vs. relaxations in absence of L-NAME (Fig. 6B) and allowed the calculation

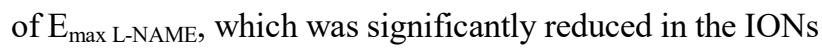
group compared to total relaxation (i.e. $\mathrm{E}_{\max }$ ). In addition, 
$\mathrm{E}_{\max \text { L-NAME }}$ for the IONs + Str group was significantly elevated compared to the IONs group (Table 1). $\mathrm{EC}_{50}$ L-NAME was shifted to higher concentrations in all groups investigated vs. $\mathrm{EC}_{50}$ without L-NAME (Table 1). The L-NAME-sensitive component, calculated from the $\mathrm{E}_{\max }$ values as a difference between $\mathrm{E}_{\max }$ and $\mathrm{E}_{\max }$ L-NAME, increased in the femoral arteries of the IONs group, but it returned to the level present in the Cont group in the femoral arteries of rats co-exposed to IONs + Str (Table 1). The AUC calculated from the cumulative concentration response curves to $\mathrm{ACh}$ in the presence of L-NAME (i.e. the L-NAME-resistant component) was significantly reduced while the L-NAME-sensitive component was significantly elevated in ION-treated rats vs. the respective control values. Moreover, the L-NAME-sensitive component of the IONs + Str group was significantly reduced compared to that of the IONs group (Fig. 6D). Pre-treatment of the arteries with the L-NAME led also to the significant reduction of relaxations at the highest ACh-concentration only in the IONs group vs. the maximal relaxation in this group at lower ACh-concentration (Fig. 6B), suggesting the release of EDCFs.

The maximal relaxations induced by cumulative concentrations of the exogenous NO donor SNP were not altered significantly in any group vs. the control group (Table 1, Fig. 6C). The sensitivity of the femoral arteries to $\mathrm{SNP}$ expressed as $\mathrm{EC}_{50}$ was significantly decreased in the IONs and IONs + Str groups vs. the control group (Table 1).

\section{IONs-originated iron contents}

ION-originated iron was present mainly in whole blood, lower amounts were present in the liver and kidneys (Fig. 7). In blood (Fig. 7A) and liver (Fig. 7B), stress reduced IONs-originated iron content by approximately $92 \%$ and $69 \%$ vs. IONs group $(p<0.04$ for both). On the other hand, ION-originated iron content increased significantly in the kidneys (Fig. 7C) by $296 \%$ $(\mathrm{p}<0.03)$.

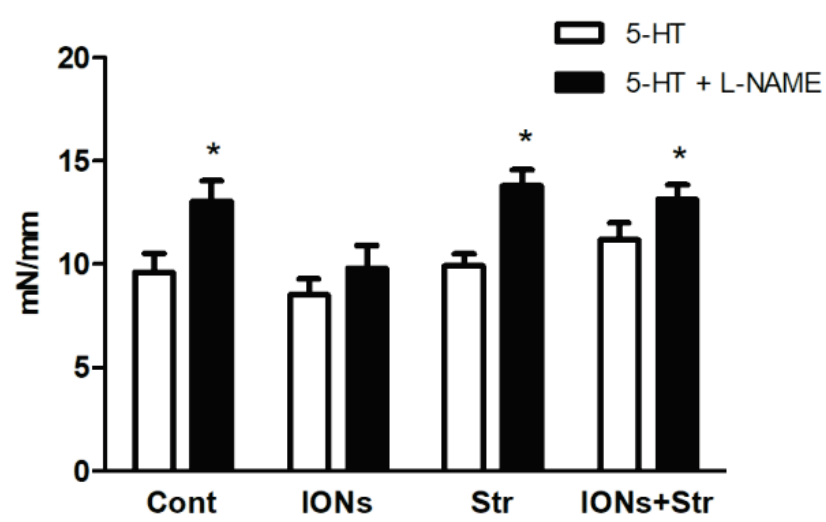

Fig. 5. Maximal serotonin (5-hydroxytryptamine)-induced contractions in the absence and presence of NO synthase inhibitor L-NAME. The values represent the mean \pm SEM. ${ }^{*} \mathrm{p}<0.05$ vs. $5-\mathrm{HT}, \mathrm{n}=6-7$ per group. Abbreviations. Cont: control group, IONs: rats treated with ultra-small superparamagnetic iron oxide nanoparticles, Str: rats exposed to repeated air jet stress, IONs + Str: rats treated with nanoparticles and co-exposed to repeated air jet stress, 5-HT: 5-hydroxytryptamine, L-NAME: $\mathrm{N}^{\omega}$-nitro-L-arginine methyl ester.

Table 1. Parameters of endothelium-independent and endothelium-dependent relaxations induced by sodium nitroprusside and acetylcholine, respectively.

\begin{tabular}{|c|c|c|c|c|}
\hline Parameter/Group & Cont & IONs & Str & IONs + Str \\
\hline \multicolumn{5}{|c|}{ Sodium nitroprusside-induced relaxations } \\
\hline$E C_{50}(-\log \mathrm{mol} / \mathrm{l})$ & $8.41 \pm 0.04$ & $8.14 \pm 0.08^{*}$ & $8.22 \pm 0.07$ & $8.10 \pm 0.06^{*}$ \\
\hline$E_{\max }(\%)$ & $98.30 \pm 0.79$ & $99.57 \pm 1.28$ & $97.15 \pm 1.24$ & $98.60 \pm 0.75$ \\
\hline \multicolumn{5}{|c|}{ Acetylcholine-induced relaxations } \\
\hline$E C_{50}(-\log \mathrm{mol} / \mathrm{l})$ & $7.58 \pm 0.05$ & $7.58 \pm 0.12$ & $7.86 \pm 0.12$ & $7.48 \pm 0.11$ \\
\hline$E_{\max }(\%)$ & $92.68 \pm 0.94$ & $90.65 \pm 1.17$ & $91.01 \pm 1.39$ & $92.40 \pm 1.05$ \\
\hline$E C_{50 \text { L-NAME }}(-\log \mathrm{mol} / \mathrm{l})$ & $7.11 \pm 0.13^{* *}$ & $7.03 \pm 0.13^{* *}$ & $6.98 \pm 0.07^{* *}$ & $6.89 \pm 0.10^{* *}$ \\
\hline$E_{\text {max L-NAME }}(\%)$ & $85.60 \pm 2.40$ & $62.20 \pm 6.23 * *$ & $83.83 \pm 2.68$ & $84.28 \pm 6.68^{+}$ \\
\hline$E_{\text {max L-NAME-sensitive }}(\%)$ & $7.07 \pm 2.59$ & $28.45 \pm 6.71^{*}$ & $7.19 \pm 2.10$ & $8.11 \pm 6.10^{+}$ \\
\hline
\end{tabular}

The values represent the mean $\pm \mathrm{SEM} .{ }^{*} \mathrm{p}<0.05$ vs. the control group, ${ }^{*} \mathrm{p} p<0.05$ vs. the same parameter without $\mathrm{L}-\mathrm{NAME},{ }^{+} \mathrm{p}<0.05$ vs. IONs group, $n=6-7$ per group. Abbreviations. Cont: control group, IONs: rats treated with ultra-small superparamagnetic iron oxide nanoparticles, Str: rats exposed to repeated air jet stress, IONs + Str: rats treated with nanoparticles and co-exposed to repeated air jet stress, L-NAME: $\mathrm{N}^{\omega}$-nitro-L-arginine methyl ester, $\mathrm{EC}_{50}$ : half-maximal effective concentration, $\mathrm{EC}_{50} \mathrm{~L}$-NAmE: half-maximal effective concentration in the presence of L-NAME, $E_{\max }$ : maximal relaxation, $E_{\max L-N A M E}$ : maximal relaxation in the presence of L-NAME. 
A

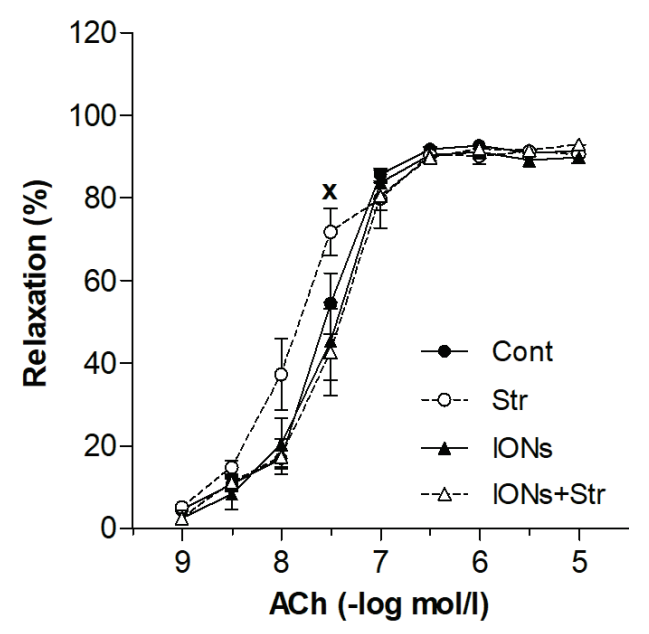

C

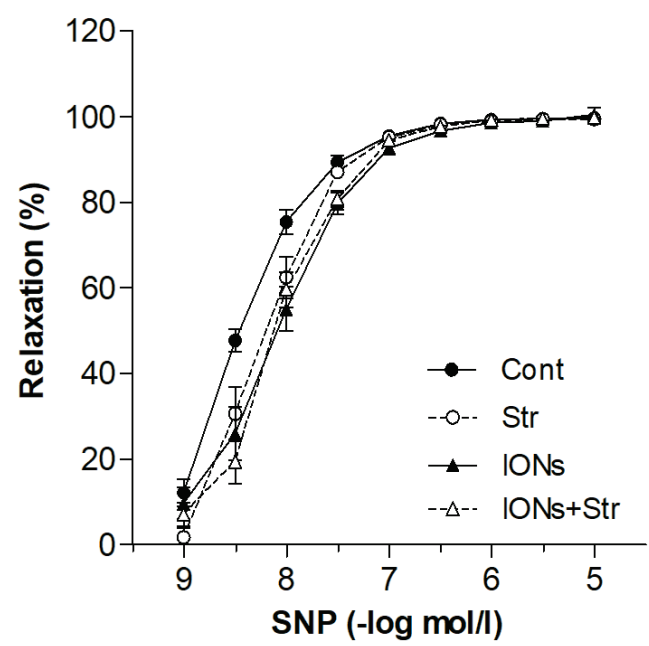

B

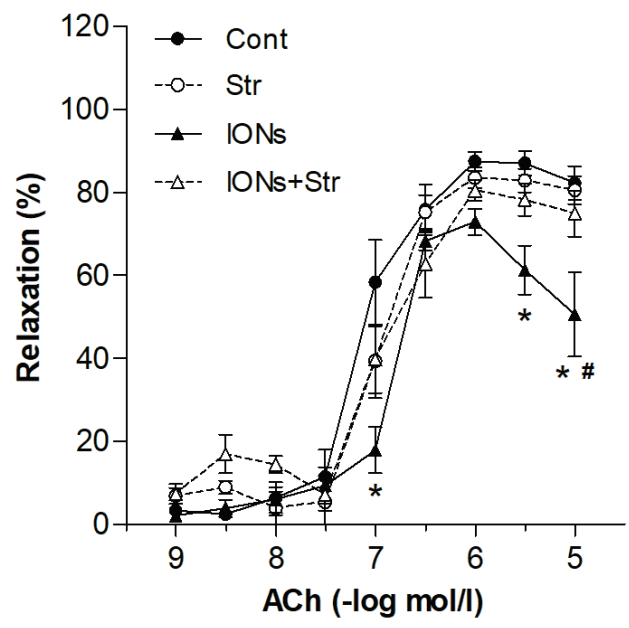

D

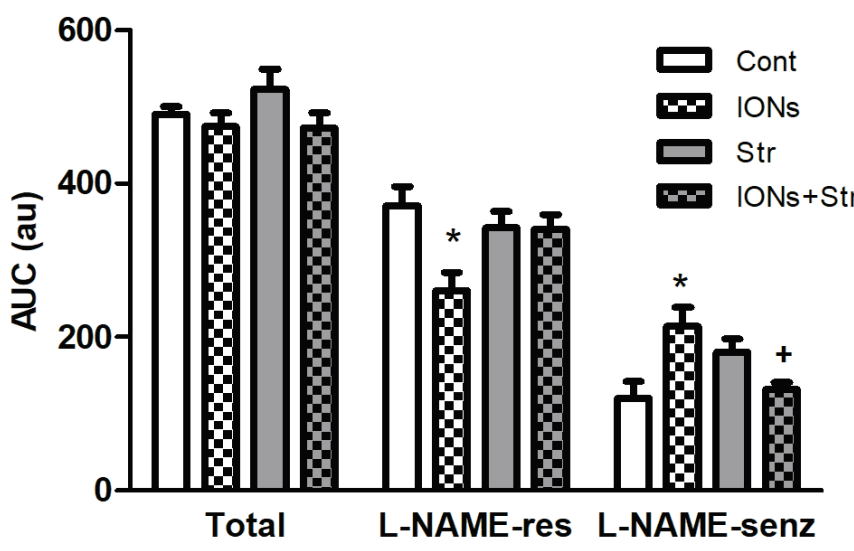

Fig. 6. Acetylcholine-induced relaxations in the absence (A) and presence (B) of L-NAME, sodium nitroprusside-induced relaxation (C) and L-NAME-sensitive and L-NAME-resistant components of acetylcholine-induced relaxations (D) in the femoral arteries. The values represent the mean \pm SEM, $n=6-7$ per group. ${ }^{x} p<0.001$ vs. the IONs + Str group, ${ }^{*} p<0.05$ vs. the same parameter of the control group, ${ }^{*} \mathrm{p}<0.02$ vs. the maximal relaxation in the IONs group (at ACh concentration $\left.10^{-6} \mathrm{~mol} / \mathrm{l}\right),{ }^{+} \mathrm{p}<0.05 \mathrm{vs}$. the same parameter in the IONs group. Abbreviations. Cont: control group, IONs: rats treated with ultra-small superparamagnetic iron oxide nanoparticles, Str: rats exposed to repeated air jet stress, IONs + Str: rats treated with nanoparticles and co-exposed to repeated air jet stress, ACh: acetylcholine, L-NAME: $\mathrm{N}^{\omega}$-nitro-L-arginine methyl ester.

A

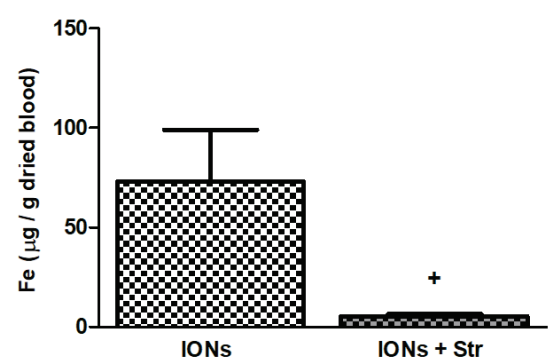

B

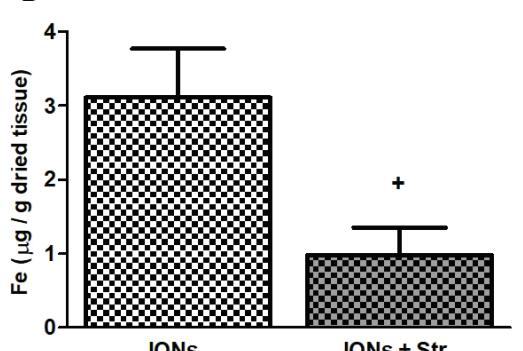

C

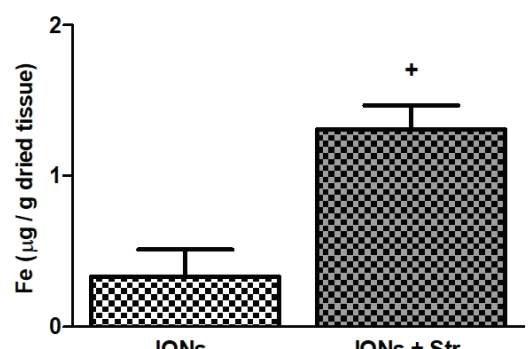

Fig. 7. IONs-originated iron content in blood (A), liver (B) and kidney $(\mathbf{C})$ in IONs and IONs + Str groups. The values represent the mean \pm SEM, $n=5-6$ per group. ${ }^{+} p<0.04$ vs. the IONs group. Abbreviations. IONs: rats treated with ultra-small superparamagnetic iron oxide nanoparticles, IONs + Str: rats treated with nanoparticles and co-exposed to repeated air jet stress. 

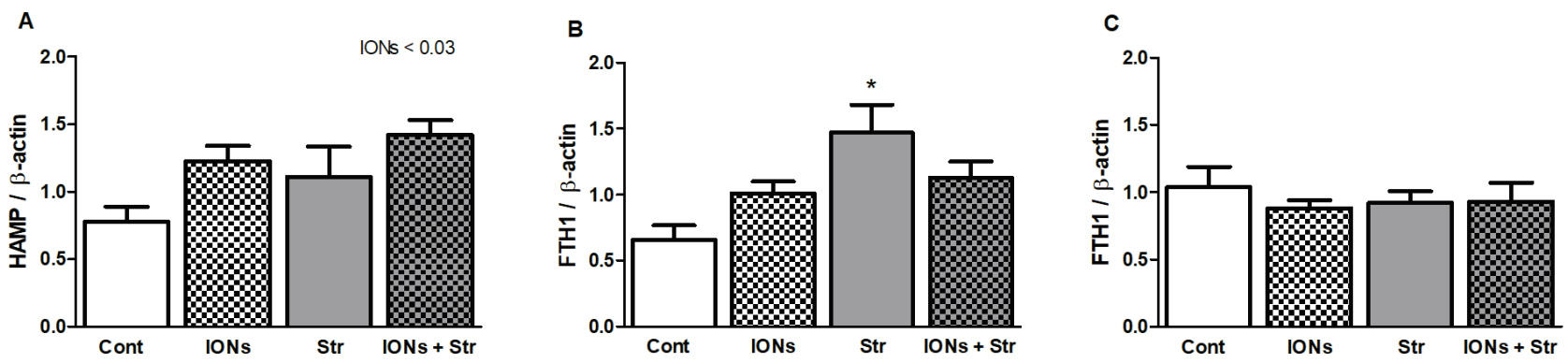

Fig. 8. The expression levels of hepcidin gene in the liver $(\mathbf{A})$ and ferritin heavy chain 1 in the liver (B) and kidneys (C). The values represent the mean \pm SEM. ${ }^{*} p<0.006$ vs the control group, $p<0.03$ main effect of IONs vs. ION-untreated groups, $n=5-6$ per group. Abbreviations. HAMP: hepcidin gene, FTH1: ferritin heavy chain 1 gene, Cont: control group, IONs: rats treated with ultra-small superparamagnetic iron oxide nanoparticles, Str: rats exposed to repeated air jet stress, IONs + Str: rats treated with nanoparticles and co-exposed to repeated air jet stress.

\section{Gene expressions}

Expression of the HAMP gene in the liver was significantly elevated when determined as the main effect of ION-administration $\left(\mathrm{F}_{(1,17)}=6.00, \mathrm{p}<0.03\right)$ (Fig. 8A). Despite tendency of higher FTH1 gene expression in the liver of ION-treated rats was observed, this did not reach statistically significant effect vs. the control group. In contrast, stress significantly elevated FTH1 gene expression in the liver by $122 \%$ vs. control $(p<0.006$, Fig. $8 \mathrm{~B}$ ). In the kidneys, no changes in the FTH1 gene expression were observed (Fig. 8C).

\section{Discussion}

This study investigated the effect of intravenously administered ultra-small PEG-coated IONs and its interaction with acute stress on vascular function, NOS activity, BP and HR and expression of HAMP and FTH1 genes in Wistar-Kyoto rats (WKY). The main findings are that IONs modified the vascular function of the femoral arteries. In these arteries IONs 1) increased the L-NAME-sensitive component of ACh-induced relaxations, 2) decreased the sensitivity of the vascular smooth muscle cells (VSMCs) to exogenous NO, 3) prevented the increase of 5-HT-induced contractions after L-NAME, and 4) induced EDCFs release in L-NAME pre-treated arteries. IONs also enhanced NOS activity in the brainstem and hypothalamus and reduced NOS activity in the kidneys. Notably, the combination of IONs with repeated acute air jet stress had no effects on the overall endothelium-dependent relaxations but altered NOS activity in the tissues and IONs-originated iron content in blood and tissues compared to IONs alone. In addition, in IONs + Str group IONs increased AJ-induced pressor responses, but decreased MAP determined 100-min post-infusion compared to basal value, which was not found in any other group of rats. In the groups of rats exposed to acute air jet stress, we found increased concentrations of plasma corticosterone, which are in line with previous results evaluating the effects of this stressor (Stojicić et al. 2008, Wsol et al. 2020). These data prove that the intensity and duration of the stressor were effective in inducing stress response.

Various studies have examined the cardiovascular effects of IONs. In human cardiac microvascular endothelial cells, IONs have not altered the viability, membrane integrity or inflammation markers of cells (Sun et al. 2011). In Sprague-Dawley rats IONs administered once per day for 7 days, IONs have reduced infarct size, elevated superoxide dismutase activity and reduced oxidative stress and the activities of several enzyme markers of heart damage (Xiong et al. 2015). On the other hand, the i.v. administration of IONs in mice has led to oxidative stress, increased levels of reactive oxygen species and superoxide dismutase activity in the heart (Baratli et al. 2013, Bostan et al. 2016). In humans, hypotension and vasodilatation have been side effects of certain IONs when administered as contrast agents to improve magnetic resonance imaging (Wang 2011). Iversen et al. reported a transient decrease in the MAP course of 12-24 h after introducing polyacrylic acid (PAA)-coated $\gamma-\mathrm{Fe}_{2} \mathrm{O}_{3}$ nanoparticles (Iversen et al. 2013). We expected that exposure to acute stress would increase MAP and prevent possible MAP reduction after ION application. However, in our study, IONs and stress, respectively, did not alter MAPs at the end of the experiment compared to the basal MAPs. Similarly, Nunes et al. found no alterations in the MAP of rats after the infusion of three types of manganese ferrite-based magnetic NPs (Nunes et al. 2014). Surprisingly, co-exposure of ION-treated rats to acute stress in this study resulted in a significant MAP decrease at the end of 
the experiment compared to basal MAP.

Next, we investigated alterations of vascular function. This is, to the best of our knowledge, the first study that determined L-NAME-sensitive and L-NAMEresistant components of endothelium-dependent ACh-induced relaxation after ION administration. Regarding vasorelaxation, $\mathrm{NO}$ is the master of endothelium-dependent relaxation (Bernatova 2014), the lack of NO is associated with reduced vasorelaxation and BP elevation (Rauchová et al. 2005). However, the effect of stress on vasculature varies depending on the model, duration and intensity of stress as well as on artery type (Puzserova and Bernatova 2016). In this study, we found that IONs alone as well as interacting with acute stress significantly reduced the sensitivity of VSMCs to the exogenous NO donor SNP (expressed as increased $\mathrm{EC}_{50}$ in SNP-induced relaxations) compared to the control group without changes in maximal SNP-induced relaxation. The effect of stress alone was not significant in this parameter. This suggests that IONs reduced the sensitivity of VSMCs to NO. The reduction of sensitivity to NO may result from the deleterious effect of IONs on VSMCs and/or from elevated NO release from the endothelium. We found the greatest L-NAME-sensitive component of ACh-induced relaxation in ION-treated rats which might result from greater NO bioavailability and/or from elevated ION-induced EDCFs release. As we also found elevated ION-induced superoxide release in the tissues of rats, including the aorta (Škrátek et al. 2020), the elevated EDCFs release is plausible in the ION-treated rats. The release of EDCFs was visible in this study at the end of ACh-concentration-response curves (in the presence of L-NAME) in ION-treated rats as the decrease of ACh-induced relaxation at the highest concentration compared to maximal ACh-induced relaxation in the given group (achieved at lower $\mathrm{ACh}$ concentration, Fig. 6B) and it was attenuated by exposure to repeated acute stress. Such a release of EDCFs is common in spontaneously hypertensive rats or in aged WKY supposedly due to a lack of inhibitory influence of NO on the release of the EDCFs (Liskova et al. 2011, Puzserova et al. 2013). On the other hand, application of L-NAME failed to elevated 5-HT-induced vasocontractions in ION-treated rats. This finding, again points to elevated NO bioavailability in the ION-treated rats because the inhibitory effect of NO on 5-HT and noradrenaline-induced contractions in the femoral arteries has been shown previously in non-stressed rats (Liskova et al. 2011, Puzserova et al. 2013) as well as in stressed ones (Slezak et al. 2014). Thus, the changes in vascular wall function after IONs application are complex and additional, more specific, experiments are needed to identify the exact mechanism responsible for alterations in vascular function in rats after administration of PEG-coated IONs.

The mechanism of functional changes in vasculature after i.v. administration of IONs lacks attention in the literature. Recent studies have shown no direct effects of increasing concentrations of $\mathrm{Fe}_{3} \mathrm{O}_{4}$ nanoparticles (size $50-100 \mathrm{~nm}$, in vitro cumulative administration) on the contractility of human mesenteric arteries (Vukova et al. 2016). Nunes et al. found mild relaxation of isolated rat aortic rings using cumulative in vitro application of bare manganese ferrite-based magnetic NPs (Nunes et al. 2014). Iversen et al. reported that in vitro incubation of small mesenteric arteries from healthy mice with PAA-coated $\gamma-\mathrm{Fe}_{2} \mathrm{O}_{3}$ nanoparticles reduced maximal contractions in response to increasing concentrations of noradrenaline (Iversen et al. 2013). Furthermore, the application of PAA-coated $\gamma-\mathrm{Fe}_{2} \mathrm{O}_{3}$ nanoparticles for $24 \mathrm{~h}$ in vivo reduced the maximal contractions of small mesenteric arteries to noradrenaline in mice, which gradually disappeared and was absent on the $7^{\text {th }}$ day of nanoparticle exposure (Iversen et al. 2013). The important finding of our study is that exposure to acute repeated stress and co-exposure to IONs and stress failed to aggravate the vascular functions of WKY rats. In fact, stress reduced ION-induced alterations (except for reduced sensitivity of VSMCs to exogenous NO), which may result from the high blood flow-induced shear stress and alterations of $\mathrm{NO}$ and/or EDCFs release by endothelial NOS during acute stress [for review see (Puzserova and Bernatova 2016)]. However, it may also result from a reduction of IONs amount in blood of rats co-exposed to stress as what we have shown in this study. It is worthy to mention that the vascular effects of NPs of different chemical moiety investigated in various experimental conditions (e.g. route of administration, dose, duration of treatment, various pre-contraction agents, artery type, etc.) may affect different physiological and molecular mechanisms (Courtois et al. 2010).

In our study, in addition to vascular functions, we investigated NOS activity in the hypothalamus, brainstem and kidneys, since those structures affect BP regulation in both normal and stressed conditions. We found augmented NOS activity in the brainstem and hypothalamus but decreased NOS activity in the kidneys 
of ION-treated rats. The enhancement of NOS activity in brain structures could lead to sympathoinhibition (Kumagai et al. 2012). Kishi showed that NO derived from the overexpression of endothelial NOS in the rostral ventrolateral medulla in the brainstem caused sympathoinhibition (Kishi 2013). Next, within the hypothalamic paraventricular nucleus, NO generated by neuronal NO synthase played a major constitutive role in suppressing ongoing renal sympathetic activity and regulating arterial pressure in Wistar rats (McBryde et al. 2018). As documented previously, a well-known crosslink exists between the brain (i.e. SNS and/or CNS) and kidney (i.e. the renin-angiotensin-aldosterone system) as well as NO and kidney functions in the regulation of BP (Kishi 2013, McBryde et al. 2018, Pecháňová et al. 2006, Drábková et al. 2020). Thus, we assume that enhanced NOS activity in the given brain structures may lead to sympathoinhibition possibly manifested in decreased NOS activity in the kidneys of ION-treated rats, leading to maintenance of unaltered levels of BP. Interestingly, in the IONs + Str group, stress blocked the increase of NOS activity in both brain structures and prevented the decrease in NOS activity in the kidneys compared to the IONs group. We assume that the simultaneous influence of two independent stressors could cause dysregulation of BP regulatory systems, which led to a temporary decrease of the resting MAP in the IONs + Str group. In addition, the decrease of MAP at rest in the IONs + Str group may, at least partially, results from elevated NOS activity in the liver. It is well known that the high production of inducible NOS-derived NO and/or other vasodilators in the liver leads to reduced systemic vascular resistance and hypotension (El Hadi et al. 2020). Thus, our results suggest that IONs have a complex effect on BP regulation, which includes the hypothalamus, brainstem, kidneys, liver and vasculature. Our findings also point to the importance of acute stress during ION-administration that might reduce the amount of IONs in circulation. In particular, IONs i.v. administration resulted in greater BP rise after air jet stress (AJ2 and AJ3, Fig. 2C) that may alter the blood flow leading to elevated IONs decomposition and/or iron storage in the liver and to the decrease of IONs-originated iron in blood of IONs + Str rats. Our findings of elevated HAMP gene expression suggest elevated systemic iron levels in IONs-exposed rats. Despite the organism lacks regulated mechanism of excretion of iron itself, IONs bigger than $6 \mathrm{~nm}$ can be excreted via hepatobiliary clearance. Furthermore, if IONs are decomposed to the particles smaller than $6 \mathrm{~nm}$, renal excretion of IONs can also participate in reduction of ION-derived iron in blood (Zhang et al. 2016). Because we did not measured IONs in urine and feces, we cannot exclude any of these routes.

\section{Conclusions}

Collectively, our results indicate that single i.v. administration of a low dose of PEG-coated IONs altered mechanisms of vascular wall function of increased NO and/or EDCFs release in vascular wall of femoral arteries, as manifested by enhanced L-NAME-sensitive component of ACh-induced relaxation, by the reduction of sensitivity to exogenous $\mathrm{NO}$ and by the absence of augmentation of 5-HT-induced contractions after NOS inhibition. These effects of IONs were reduced when rats were exposed also to repeated acute stress despite acute stress itself having no effect on these parameters. In addition, joint exposure of ION-treated rats to repeated acute stress reduced ION-originated iron in blood and liver, affected NOS activity and altered the mechanisms of $\mathrm{BP}$ regulation, resulting in enhanced pressor responses to stress, but reduced MAP at rest. Our findings thus point to considerable involvement of acute stress in clearance and/or tissue distribution of IONs associated with alterations in vascular function and BP regulation after a single i.v. IONs application.

\section{Conflict of Interest}

There is no conflict of interest.

\section{Acknowledgements}

The authors thank Mrs. J. Petova and Mrs. B. Bolgacova for their technical assistance. This research was funded by the research grants APVV-16-0263, VEGA 2/0160/17, APVV-17-0178, and SAV-BAV-18-11.

\section{References}

ALMEIDA JP, CHEN AL, FOSTER A, DREZEK R: In vivo biodistribution of nanoparticles. Nanomedicine (Lond) 6: 815-835, 2011. https://doi.org/10.2217/nnm.11.79 
ANDRADE RGD, VELOSO SRS, CASTANHEIRA EMS: Shape anisotropic iron oxide-based magnetic nanoparticles: synthesis and biomedical applications. Int J Mol Sci 21: 2020. https://doi.org/10.3390/ijms21072455

ASTANINA K, SIMON Y, CAVELIUS C, PETRY S, KRAEGELOH A, KIEMER AK: Superparamagnetic iron oxide nanoparticles impair endothelial integrity and inhibit nitric oxide production. Acta Biomater 10: 4896-4911, 2014. https://doi.org/10.1016/j.actbio.2014.07.027

BARATLI Y, CHARLES AL, WOLFF V, BEN TAHAR L, SMIRI L, BOUITBIR J, ZOLL J, PIQUARD F, TEBOURBI O, SAKLY M, ABDELMELEK H, GENY B: Impact of iron oxide nanoparticles on brain, heart, lung, liver and kidneys mitochondrial respiratory chain complexes activities and coupling. Toxicol In Vitro 27: 2142-2148, 2013. https://doi.org/10.1016/j.tiv.2013.09.006

BEHULIAK M, PINTEROVA M, BENCZE M, PETROVA M, LISKOVA S, KAREN P, KUNES J, VANECKOVA I, ZICHA J: $\mathrm{Ca}^{2+}$ sensitization and $\mathrm{Ca}^{2+}$ entry in the control of blood pressure and adrenergic vasoconstriction in conscious Wistar-Kyoto and spontaneously hypertensive rats. J Hypertens 31: 2025-2035, 2013. https://doi.org/10.1097/HJH.0b013e328362adb3

BENCZE M, VAVŘíNOVÁ A, ZICHA J, BEHULIAK M: Pharmacological suppression of endogenous glucocorticoid synthesis attenuated blood pressure and heart rate response to acute restraint in wistar rats. Physiol Res 69: 415-426, 2020. https://doi.org/10.33549/physiolres. 934432

BENCZE M, BEHULIAK M, VAVRINOVA A, ZICHA J: Broad-range TRP channel inhibitors (2-APB, flufenamic acid, SKF-96365) affect differently contraction of resistance and conduit femoral arteries of rat. Eur J Pharmacol 765: 533-540, 2015. https://doi.org/10.1016/j.ejphar.2015.09.014

BERNATOVA I: Endothelial dysfunction in experimental models of arterial hypertension: cause or consequence? Biomed Res Int 2014: 598271, 2014. https://doi.org/10.1155/2014/598271

BERNATOVA I, BALIS P, GOGA R, BEHULIAK M, ZICHA J, SEKAJ I: Lack of reactive oxygen species deteriorates blood pressure regulation in acute stress. Physiol Res 65: S381-S390, 2016. https://doi.org/10.33549/physiolres. 933433

BOSTAN HB, REZAEE R, VALOKALA MG, TSAROUHAS K, GOLOKHVAST K, TSATSAKIS AM, KARIMI G: Cardiotoxicity of nano-particles. Life Sci 165: 91-99, 2016. https://doi.org/10.1016/j.lfs.2016.09.017

COURTOIS A, ANDUJAR P, LADEIRO Y, DUCRET T, ROGERIEUX F, LACROIX G, BAUDRIMONT I, GUIBERT C, ROUX E, CANAL-RAFFIN M, BROCHARD P, MARANO F, MARTHAN R, MULLER B: Effect of engineered nanoparticles on vasomotor responses in rat intrapulmonary artery. Toxicol Appl Pharmacol 245: 203-210, 2010. https://doi.org/10.1016/j.taap.2010.03.002

DALZON B, TORRES A, REYMOND S, GALLET B, SAINT-ANTONIN F, COLLIN-FAURE V, MORISCOT C, FENEL D, SCHOEHN G, AUDE-GARCIA C, RABILLOUD T: Influences of nanoparticles characteristics on the cellular responses: the example of iron oxide and macrophages. Nanomaterials (Basel) 10: 2020. https://doi.org/10.3390/nano10020266

DE DOMENICO I, ZHANG TY, KOENING CL, BRANCH RW, LONDON N, LO E, DAYNES RA, KUSHNER JP, LI D, WARD DM, KAPLAN J: Hepcidin mediates transcriptional changes that modulate acute cytokineinduced inflammatory responses in mice. J Clin Invest 120: 2395-2405, 2010. https://doi.org/10.1172/JCI42011

DOBIAS L, PETROVA M, VOJTKO R, KRISTOVA V: Long-term treatment with hesperidin improves endotheliumdependent vasodilation in femoral artery of spontaneously hypertensive rats: the involvement of NO-synthase and Kv channels. Phytother Res 30: 1665-1671, 2016. https://doi.org/10.1002/ptr.5670

DRÁBKOVÁ N, HOJNÁ S, ZICHA J, VANĚČKOVÁ I: Contribution of selected vasoactive systems to blood pressure regulation in two models of chronic kidney disease. Physiol Res 69: 405-414, 2020. https://doi.org/10.33549/physiolres.934392

DUKHINOVA MS, PRILEPSKII AY, SHTIL AA, VINOGRADOV VV: Metal oxide nanoparticles in therapeutic regulation of macrophage functions. Nanomaterials (Basel) 9: 2019. https://doi.org/10.3390/nano9111631

EL HADI H, DI VINCENZO A, VETTOR R, ROSSATO M: Relationship between heart disease and liver disease: a two-way street. Cells 9: 2020. https://doi.org/10.3390/cells9030567 
IVERSEN NK, FRISCHE S, THOMSEN K, LAUSTSEN C, PEDERSEN M, HANSEN PB, BIE P, FRESNAIS J, BERRET JF, BAATRUP E, WANG T: Superparamagnetic iron oxide polyacrylic acid coated gamma-Fe2O3 nanoparticles do not affect kidney function but cause acute effect on the cardiovascular function in healthy mice. Toxicol Appl Pharmacol 266: 276-288, 2013. https://doi.org/10.1016/j.taap.2012.10.014

KANBAR R, OREA V, CHAPUIS B, BARRES C, JULIEN C: A transfer function method for the continuous assessment of baroreflex control of renal sympathetic nerve activity in rats. Am J Physiol Regul Integr Comp Physiol 293: R1938-R1946, 2007. https://doi.org/10.1152/ajpregu.00374.2007

KENZAOUI BH, BERNASCONI CC, HOFMANN H, JUILLERAT-JEANNERET L: Evaluation of uptake and transport of ultrasmall superparamagnetic iron oxide nanoparticles by human brain-derived endothelial cells. Nanomedicine (Lond) 7: 39-53, 2012. https://doi.org/10.2217/nnm.11.85

KISHI T: Regulation of the sympathetic nervous system by nitric oxide and oxidative stress in the rostral ventrolateral medulla: 2012 Academic Conference Award from the Japanese Society of Hypertension. Hypertens Res 36: 845-851, 2013. https://doi.org/10.1038/hr.2013.73

KLUKNAVSKY M, BALIS P, SKRATEK M, MANKA J, BERNATOVA I: (-)-Epicatechin reduces the blood pressure of young borderline hypertensive rats during the post-treatment period. Antioxidants (Basel) 9: 2020. https://doi.org/10.3390/antiox9020096

KUMAGAI H, OSHIMA N, MATSUURA T, IIGAYA K, IMAI M, ONIMARU H, SAKATA K, OSAKA M, ONAMI T, TAKIMOTO C, KAMAYACHI T, ITOH H, SARUTA T: Importance of rostral ventrolateral medulla neurons in determining efferent sympathetic nerve activity and blood pressure. Hypertens Res 35: 132-141, 2012. https://doi.org/10.1038/hr.2011.208

LEE GK, MAHESHRI N, KASPAR B, SCHAFFER DV: PEG conjugation moderately protects adeno-associated viral vectors against antibody neutralization. Biotechnol Bioeng 92: 24-34, 2005. https://doi.org/10.1002/bit.20562

LISKOVA S, KUNES J, ZICHA J: Nifedipine-sensitive vascular reactivity of femoral arteries in WKY: the effects of pertussis toxin pretreatment and endothelium removal. Physiol Res 56: 663-666, 2007.

LISKOVA S, PETROVA M, KAREN P, BEHULIAK M, ZICHA J: Contribution of Ca(2+)-dependent Cl(-) channels to norepinephrine-induced contraction of femoral artery is replaced by increasing EDCF contribution during ageing. Biomed Res Int 2014: 289361, 2014. https://doi.org/10.1155/2014/289361

LISKOVA S, PETROVA M, KAREN P, KUNES J, ZICHA J: Effects of aging and hypertension on the participation of endothelium-derived constricting factor (EDCF) in norepinephrine-induced contraction of rat femoral artery. Eur J Pharmacol 667: 265-270, 2011. https://doi.org/10.1016/j.ejphar.2011.05.031

LISKOVA S, PETROVA M, KAREN P, KUNES J, ZICHA J: Influence of calcium-dependent potassium channel blockade and nitric oxide inhibition on norepinephrine-induced contractions in two forms of genetic hypertension. J Am Soc Hypertens 4: 128-134, 2010. https://doi.org/10.1016/j.jash.2010.02.006

LONGMIRE M, CHOYKE PL, KOBAYASHI H: Clearance properties of nano-sized particles and molecules as imaging agents: considerations and caveats. Nanomedicine (Lond) 3: 703-717, 2008. https://doi.org/10.2217/17435889.3.5.703

MCBRYDE FD, LIU BH, ROLOFF EV, KASPAROV S, PATON JFR: Hypothalamic paraventricular nucleus neuronal nitric oxide synthase activity is a major determinant of renal sympathetic discharge in conscious Wistar rats. Exp Physiol 103: 419-428, 2018. https://doi.org/10.1113/EP086744

MEWISSEN MW: Stenting in the femoropopliteal arterial segment. Tech Vasc Interv Radiol 8: 146-149, 2005. https://doi.org/10.1053/j.tvir.2006.05.003

NAKAMOTO M, OHYA Y, SAKIMA A, YAMAZATO M, TAKISHITA S: Azelnidipine attenuates cardiovascular and sympathetic responses to air jet stress in genetically hypertensive rats. Hypertens Res 30: 359-366, 2007. https://doi.org/10.1291/hypres.30.359

NUNES AD, RAMALHO LS, SOUZA AP, MENDES EP, COLUGNATI DB, ZUFELATO N, SOUSA MH, BAKUZIS AF, CASTRO CH: Manganese ferrite-based nanoparticles induce ex vivo, but not in vivo, cardiovascular effects. Int J Nanomedicine 9: 3299-3312, 2014. https://doi.org/10.2147/IJN.S64254

$\mathrm{OH}$ N, PARK JH: Endocytosis and exocytosis of nanoparticles in mammalian cells. Int J Nanomedicine 9 Suppl 1: 51-63, 2014. https://doi.org/10.2147/IJN.S26592 
PECHANOVA O, MATUSKOVA J, CAPIKOVA D, JENDEKOVA L, PAULIS L, SIMKO F: Effect of spironolactone and captopril on nitric oxide and S-nitrosothiol formation in kidney of L-NAME-treated rats. Kidney Int 70: 170-176, 2006. https://doi.org/10.1038/sj.ki.5001513

POLLER WC, PIEBER M, BOEHM-STURM P, RAMBERGER E, KARAMPELAS V, MOLLER K, SCHLEICHER M, WIEKHORST F, LOWA N, WAGNER S, SCHNORR J, TAUPITZ M, STANGL K, STANGL V, LUDWIG A: Very small superparamagnetic iron oxide nanoparticles: Long-term fate and metabolic processing in atherosclerotic mice. Nanomedicine 14: 2575-2586, 2018. https://doi.org/10.1016/j.nano.2018.07.013

PUZSEROVA A, BERNATOVA I: Blood pressure regulation in stress: focus on nitric oxide-dependent mechanisms. Physiol Res 65 (Suppl 3): S309-S342, 2016. https://doi.org/10.33549/physiolres. 933442

PUZSEROVA A, KOPINCOVA J, SLEZAK P, BALIS P, BERNATOVA I: Endothelial dysfunction in femoral artery of the hypertensive rats is nitric oxide independent. Physiol Res 62: 615-629, 2013. https://doi.org/10.33549/physiolres.932517

RAUCHOVÁ H, PECHÁNOVÁ O, KUNES J, VOKURKOVÁ M, DOBESOVÁ Z, ZICHA J: Chronic $\mathrm{N}$-acetylcysteine administration prevents development of hypertension in $\mathrm{N}$ (omega)-nitro-L-arginine methyl ester-treated rats: the role of reactive oxygen species. Hypertens Res 28: 475-482, 2005. https://doi.org/10.1291/hypres.28.475

SKŘÁTEK M, DVUREČENSKIJ A, KLUKNAVSKÝ M, BARTA A, BALIŠ P, MIČUROVÁ A, CIGÁŇ A, ECKSTEIN-ANDICSOVÁ A, MAŇKA J, BERNÁTOVÁ I: Sensitive SQUID bio-magnetometry for determination and differentiation of biogenic iron and iron oxide nanoparticles in biological samples. Nanomaterials 10: 1993, 2020. https://doi.org/10.3390/nano10101993

SLEZAK P, PUZSEROVA A, BALIS P, SESTAKOVA N, MAJZUNOVA M: Genotype-related effect of crowding stress on blood pressure and vascular function in young female rats. Biomed Res Int 2014: 413629, 2014. https://doi.org/10.1155/2014/413629

STEFANO GB, FRICCHIONE GL, ESCH T: Relaxation: molecular and physiological significance. Med Sci Monit 12: Hy21-Hy31, 2006.

STOJICIĆ S, MILUTINOVIĆ-SMILJANIĆ S, SARENAC O, MILOSAVLJEVIĆ S, PATON JF, MURPHY D, JAPUNDZIĆ-ZIGON N: Blockade of central vasopressin receptors reduces the cardiovascular response to

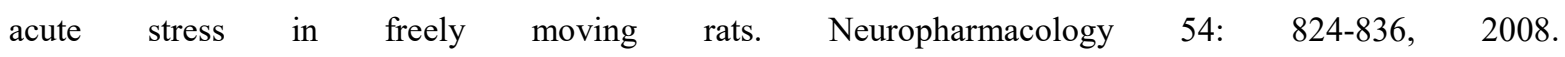
https://doi.org/10.1016/j.neuropharm.2007.12.013

SU L, HAN L, GE F, ZHANG SL, ZHANG Y, ZHAO BX, ZHAO J, MIAO JY: The effect of novel magnetic nanoparticles on vascular endothelial cell function in vitro and in vivo. J Hazard Mater 235-236: 316-325, 2012. https://doi.org/10.1016/j.jhazmat.2012.08.003

SUK JS, XU Q, KIM N, HANES J, ENSIGN LM: PEGylation as a strategy for improving nanoparticle-based drug and gene delivery. Adv Drug Deliv Rev 99: 28-51, 2016. https://doi.org/10.1016/j.addr.2015.09.012

SUN J, WANG S, ZHAO D, HUN FH, WENG L, LIU H: Cytotoxicity, permeability, and inflammation of metal oxide nanoparticles in human cardiac microvascular endothelial cells: cytotoxicity, permeability, and inflammation of metal oxide nanoparticles. Cell Biol Toxicol 27: 333-342, 2011. https://doi.org/10.1007/s10565-011-9191-9

TORTI FM, TORTI SV: Regulation of ferritin genes and protein. Blood 99: 3505-3516, 2002. https://doi.org/10.1182/blood.V99.10.3505

VUKOVA TI, DIMITROV SD, GAGOV HS, DIMITROVA DZ: In focus: $\mathrm{Fe}_{3} \mathrm{O}_{4}$ nanoparticles and human mesenteric artery interaction in vitro. Nanomedicine (Lond) 11: 921-932, 2016. https://doi.org/10.2217/nnm.16.25

WANG J, RAO H, WETMORE GS, FURLAN PM, KORCZYKOWSKI M, DINGES DF, DETRE JA: Perfusion functional MRI reveals cerebral blood flow pattern under psychological stress. Proc Natl Acad Sci U S A 102: 17804-17809, 2005. https://doi.org/10.1073/pnas.0503082102

WANG YX: Superparamagnetic iron oxide based MRI contrast agents: Current status of clinical application. Quant Imaging Med Surg 1: 35-40, 2011. 
WSOL A, WOJNO O, PUCHALSKA L, WRZESIEN R, SZCZEPANSKA-SADOWSKA E, CUDNOCHJEDRZEJEWSKA A: Impaired hypotensive effects of centrally acting oxytocin in SHR and WKY rats exposed to chronic mild stress. Am J Physiol Regul Integr Comp Physiol 318: R160-r172, 2020. https://doi.org/10.1152/ajpregu.00050.2019

XIONG F, WANG H, FENG Y, LI Y, HUA X, PANG X, ZHANG S, SONG L, ZHANG Y, GU N: Cardioprotective activity of iron oxide nanoparticles. Sci Rep 5: 8579, 2015. https://doi.org/10.1038/srep08579

YAMAZATO M, OHYA Y, NAKAMOTO M, SAKIMA A, TAGAWA T, HARADA Y, NABIKA T, TAKISHITA S: Sympathetic hyperreactivity to air jet stress in the chromosome 1 blood pressure quantitative trait locus congenic rats. Am J Physiol Regul Integr Comp Physiol 290: R709-714, 2006. https://doi.org/10.1152/ajpregu.00610.2005

YARJANLI Z, GHAEDI K, ESMAEILI A, RAHGOZAR S, ZARRABI A: Iron oxide nanoparticles may damage to the neural tissue through iron accumulation, oxidative stress, and protein aggregation. BMC Neuroscience 18: 51, 2017. https://doi.org/10.1186/s12868-017-0369-9

YOFFE S, LESHUK T, EVERETT P, GU F: Superparamagnetic iron oxide nanoparticles (SPIONs): synthesis and surface modification techniques for use with MRI and other biomedical applications. Curr Pharm Des 19: 493-509, 2013. https://doi.org/10.2174/138161213804143707

ZHANG YN, POON W, TAVARES AJ, MCGILVRAY ID, CHAN WCW: Nanoparticle-liver interactions: Cellular uptake and hepatobiliary elimination. J Control Release 240: 332-348, 2016. https://doi.org/10.1016/j.jconrel.2016.01.020

ZHU MT, WANG Y, FENG WY, WANG B, WANG M, OUYANG H, CHAI ZF: Oxidative stress and apoptosis induced by iron oxide nanoparticles in cultured human umbilical endothelial cells. J Nanosci Nanotechnol 10: 8584-8590, 2010. https://doi.org/10.1166/jnn.2010.2488 